\title{
Mathematical Modelling of Venom Immunotherapy
}

\author{
JAN RICHTER ${ }^{\mathrm{a}, \mathrm{b}, *}$, GERHARD METZNER ${ }^{\dagger^{a}}$ and ULRICH BEHN ${ }^{\ddagger^{\mathrm{b}}}$ \\ ${ }^{\mathrm{a}}$ Institute for Clinical Immunology and Transfusion Medicine, University of Leipzig, Johannisallee 30, Leipzig D-04103, Germany; ${ }^{\mathrm{b}}$ Institute for \\ Theoretical Physics, University of Leipzig, Vor dem Hospitaltore 1, Leipzig D-04103, Germany
}

(Received 27 February 2001; Revised 10 January 2002)

\begin{abstract}
Allergic hypersensitivity of type I for hymenoptera venoms is the most frequent reason for acute $\operatorname{IgE}$ mediated anaphylactic reactions. The subcutaneous injection of increasing doses of purified allergen followed by long-term administration of an adequate maintenance dose over a period of $3-5$ years called venom immunotherapy (VIT) has been proven to be a very effective treatment achieving protection in about $96 \%$ of allergic patients. Even though the principle of hyposensitisation has been introduced already 90 years ago, the underlying immunoregulatory mechanisms of VIT remain poorly understood. Recent studies suggest a shift in cytokine production from a Th2 to a Th1 cytokine profile during therapy. In this paper, a mathematical model for T-cell regulation and a model for mast cell/basophil desensitisation are presented and analysed to explain the mechanism of conventional rush and ultra-rush VIT.
\end{abstract}

Keywords: Mathematical model; Allergy; Venom immunotherapy; Desensitisation

\section{TH1-TH2 REGULATION AND ALLERGY}

Over the last decade it has become clear that the capability of various subsets of $\mathrm{CD}^{+}{ }^{+}$class II MHC-restricted T-cells (helper T-cells) to generate certain cytokines in response to allergen is crucial for the regulation of IgE synthesis and the generation of inflammatory responses (Mosmann et al., 1986; Romagnani, 1991). The concept of T-helper cell heterogeneity is based on a marked difference in their cytokine secretion patterns. One subtype of T-helper cells, referred to as Th2-cells, produces mainly cytokines such as IL-3, IL-4, IL-5, and IL-13, providing defence against extracellular pathogens. The other T-helper subtype, Th1, producing cytokines such as IL-2, IL-12, and IFN- $\gamma$, is involved in immune responses against intracellular pathogens such as viruses and tends to antagonise the allergic response. Recently the CC-chemokine receptor 5 (CCR5) has been described as a surface marker of Th1 cells (Odum et al., 1999), whereas the relationship between CD30 expression and Th2 cells is still controversial (Hamann et al., 1996; Petkova et al., 2000).

Factors influencing the differentiation of $\mathrm{CD} 4^{+} \mathrm{T}$ cells comprise the affinity of the allergen peptide to the MHC
(Chaturvedi et al., 1996; Murray, 1998), the dose of the allergen (Kumar et al., 1995; Parish and Liew, 1972; Ruedl et al., 2000), the type of antigen presenting cell (APC) (Kapsenberg et al., 1998), selective use of costimulatory molecules, or the cytokine microenvironment during stimulation (Romagnani, 1993; Seder et al., 1993; Swain et al., 1990). In addition to the expression of distinct cytokines, the molecular basis for commitment to a Th1 or Th2 phenotype can probably explained by multiple mechanisms including differential cytokine signalling, exclusive cytokine receptor expression, differential expression of transcription factors or differential chromatin remodelling of Th1- and Th2-specific genes (Agarwal and Rao, 1998; Murphy et al., 1999; Rincon and Flavell, 1997; Takemoto et al., 2000).

Figure 1 represents a simplified scheme of the proposed cellular and molecular mechanisms of allergy. Antigen presenting cells such as dendritic cells or B-cells trigger naïve $\mathrm{CD}^{+}{ }^{+} \mathrm{T}$-cells to differentiate into Th1- or Th2-cells. Cytokines released by Th2-cells (IL-4, IL-5, IL-10) have the following effects: autocrine stimulation of the Th2-cell population, suppression of IFN- $\gamma$ production in Th1-cells, IgE production in B-cells and activation of eosinophils and

\footnotetext{
*Corresponding author. Address: Institute for Clinical Immunology and Transfusion Medicine, University of Leipzig, Johannisallee 30, Leipzig D04103, Germany. E-mail: jan.richter@physik.uni-leipzig.de

${ }^{\dagger}$ E-mail: metznerg@medizin.uni-leipzig.de

E-mail: behn@itp.uni-leipzig.de
} 


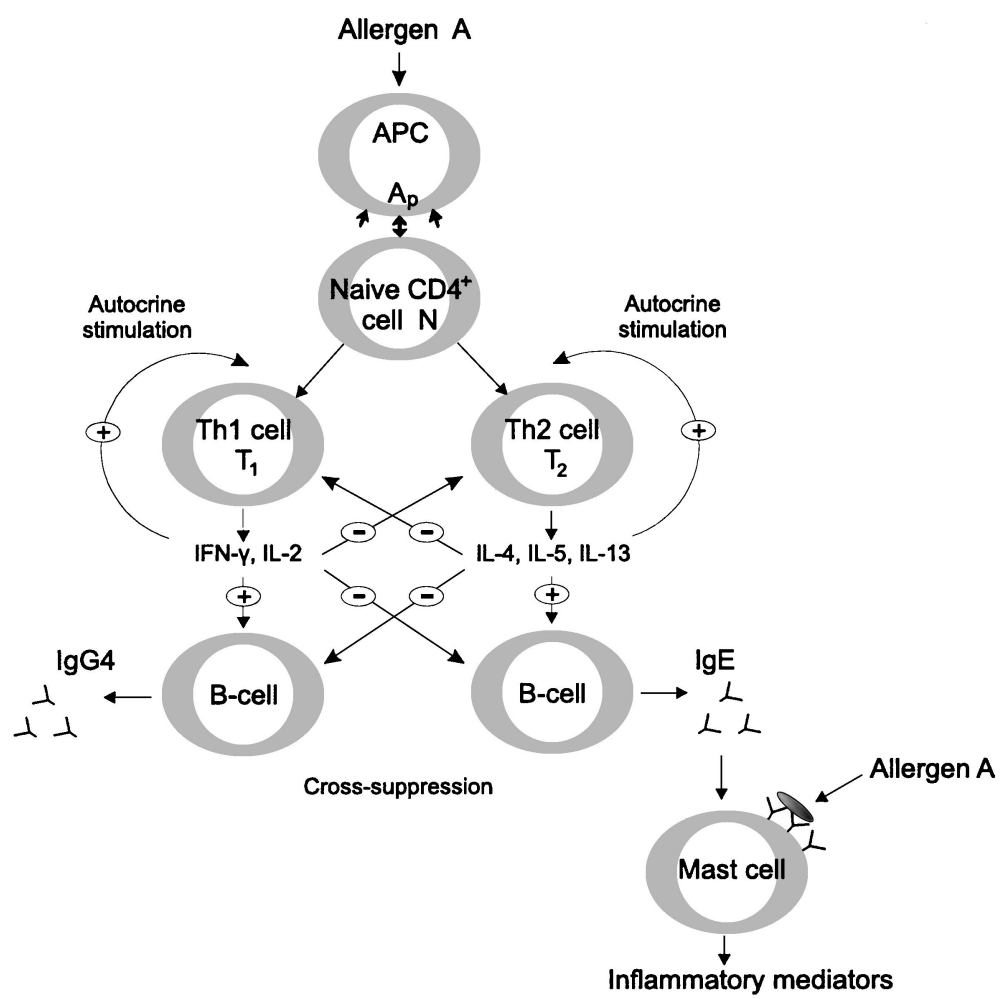

FIGURE 1 Th1-Th2 regulation via cross-suppressive and autocrine cytokines, their effect on the antibody secretion by B-cells and the sensitisation of mast cells.

basophils. Th1 cytokines on the other hand have autocrine effects on production of Th1-cells, suppress proliferation of Th2-cells and cause B-cells to produce IgG4 (Abbas et al., 1996; Romagnani, 1997).

Allergy of type I is a typical Th2-response (Romagnani, 1996). Cross-linking of specific IgE antibodies on the mast cell or basophil surface by allergen leads to a subsequent mediator release by these cells and promotes thereby the allergic reaction.

Hyposensitisation was first introduced 1911 by Noon to treat patients suffering from hay fever by injecting them with pollen extracts (Noon and Cantab, 1911). Since then this method has been adopted as the treatment of choice for allergic hypersensitivity. The effectiveness of immunotherapy has been proven in several clinical studies (Hunt et al., 1978; Reisman, 1992). In patients undergoing venom immunotherapy (VIT) a shift from a Th2 to a Th1 profile and an increase of the specific $\mathrm{IgG} 4 / \mathrm{IgE}$ ratio (Blaser et al., 1998; McHugh et al., 1995; Schuerwegh et al., 2001; Tari et al., 1994) has been observed.

We suppose that in immunotherapy two phases, which target different types of cells, can be distinguished. The first phase comprises the initiation phase, which starts with very low doses of the allergen continued by gradually increasing doses and is supposed to desensitise the effector cells of the early phase reaction, i.e. mast cells and basophils. Thus having eliminated the danger of anaphylactic reactions it is possible to administer high doses of the allergen, which select for Th1 responses, over a period of 3-5 years to eventually perform a Th2 $\rightarrow$ Th1 switch, which is, however, of transient nature (Golden et al., 2000). Out of this complex network of immune regulation, two models describing the essential processes that govern these two different phases of the therapy have been developed and are discussed in the following section.

\section{THE MATHEMATICAL MODELS}

\section{Th1/Th2-cell Regulation}

For the T-cell regulation, the mathematical model proposed by Behn et al. (2001) is adopted. We use, however, a fundamentally different parameter regime as suggested by recent experimental findings (Ruedl et al., 2000; Secrist et al., 1995). The model comprises initially six variables, namely the concentration of naïve cells $(\hat{N})$, the concentration of either T-helper cell population $\left(\hat{T}_{1}\right.$ and $\hat{T}_{2}$ ), the concentration of allergen peptide presented by APCs $\left(\hat{A}_{\mathrm{p}}\right)$, the cytokines secreted by Th1-cells all of them denoted by IF, and the cytokines secreted by Th2-cells denoted by IL. Since the life-time of cytokines is short compared to that of T-cells, cytokines relax fast to a quasistationary state, which allows for an elimination of these two variables. Measuring the time in units of half-life of the $\mathrm{T}$-cells and rescaling the variables, yields the 
following set of equations (see Appendix for details):

$$
\begin{gathered}
\frac{\mathrm{d} N}{\mathrm{~d} t}=-N+\alpha-N A_{\mathrm{p}}\left(\frac{T_{1}}{1+\mu_{2} T_{2}}+c\right)-\phi N A_{\mathrm{p}}\left(T_{2}+c\right) \\
\frac{\mathrm{d} T_{1}}{\mathrm{~d} t}=-T_{1}+v N A_{\mathrm{p}}\left(\frac{T_{1}}{1+\mu_{2} T_{2}}+c\right) \\
\frac{\mathrm{d} T_{2}}{\mathrm{~d} t}=-T_{2}+v \phi N A_{\mathrm{p}} \frac{T_{2}+c}{1+\mu_{1} \frac{T_{1}}{1+\mu_{2} T_{2}}} \\
\frac{\mathrm{d} A_{\mathrm{p}}}{\mathrm{d} t}=\xi_{\mathrm{p}}(t)-A_{\mathrm{p}}\left(T_{1}+T_{2}\right)
\end{gathered}
$$

where $\alpha$ is the production rate of the naïve T-cells, $v$ is the proliferation rate of the T-cells and $\xi_{\mathrm{p}}(t)$ is the rate at which allergen peptide is presented by APCs after an allergen injection. The dimensionless parameters $\mu_{1}$ and $\mu_{2}$ control the efficiency of the cross-suppression of Th1- and Th2-cells mediated by their cytokines and become important at high concentrations, whereas $\phi$ regulating the balance of the autocrine effects of the Th1-Th2 system is relevant at low concentrations. A small cytokine background originating from other immunological processes is accounted for by the parameter $c$, which has been assumed to be constant in time.

\section{Fixed Points of the Autonomous System}

In the following, the state of the system will be denoted by

$$
\vec{Z}=\left(N, T_{1}, T_{2}, A_{\mathrm{p}}\right) .
$$

Neglecting the small cytokine background $(c=0)$ the system has, without allergen $\left(\xi_{\mathrm{p}}(t)=0\right)$, only one fixed point: $\vec{Z}^{0}=(\alpha, 0,0,0)$. For a constant allergen supply $\xi_{\mathrm{p}}(t)=\xi_{\mathrm{p}}>0$, the system has two stable fixed points

$$
\begin{gathered}
\vec{Z}_{a}=\left(\frac{\alpha}{1+\xi_{\mathrm{p}}}, \frac{v \alpha \xi_{\mathrm{p}}}{1+\xi_{\mathrm{p}}}, 0, \frac{1+\xi_{\mathrm{p}}}{v \alpha}\right), \\
\vec{Z}_{b}=\left(\frac{\alpha}{1+\phi \xi_{\mathrm{p}}}, 0, \frac{v \alpha \phi \xi_{\mathrm{p}}}{1+\phi \xi_{\mathrm{p}}}, \frac{1+\phi \xi_{\mathrm{p}}}{v \alpha \phi}\right) .
\end{gathered}
$$

These fixed points describe states in which either the Th1- or the Th2-cell population dominates and the other becomes extinct. Allowing for a small cytokine background $c$, the fixed points can be written as

$$
\begin{aligned}
& \vec{Z}_{a}^{\prime}=\vec{Z}_{a}+c \vec{Z}^{\prime}, \\
& \vec{Z}_{b}^{\prime}=\vec{Z}_{b}+c \vec{Z}^{\prime \prime} .
\end{aligned}
$$

The correction $\vec{Z}^{\prime}$ for the Th1-cell dominating fixed point $\vec{Z}_{a}$ reads

$$
\begin{gathered}
T_{2}^{\prime}=\frac{\phi}{\mu_{1} T_{1, a}-\phi+1}, \\
N^{\prime}=\frac{\left(\mu_{2} T_{1, a}-\phi+1\right) T_{2}^{\prime}-(\phi+1)}{v\left(1+\xi_{\mathrm{p}}\right)}, \\
T_{1}^{\prime}=v \xi_{\mathrm{p}} N^{\prime}-\left(\mu_{2} T_{1, a}+1\right) T_{2}^{\prime}+1, \\
A_{\mathrm{p}}^{\prime}=-\left(A_{\mathrm{p}, a}\right)^{2}\left(T_{1}^{\prime}+T_{2}^{\prime}\right) / \xi_{\mathrm{p}} .
\end{gathered}
$$

The correction $\vec{Z}^{\prime \prime}$ for the Th2-cell dominating fixed point $\vec{Z}_{b}$ is

$$
\begin{gathered}
T_{1}^{\prime \prime}=\frac{1+\mu_{2} T_{2, b}}{\phi\left(1+\mu_{2} T_{2, b}\right)-1}, \\
N^{\prime \prime}=\frac{-\left(\mu_{2} T_{2} b-\phi+1\right) T_{1}^{\prime \prime}-(\phi+1)}{v \phi\left(1+\phi \xi_{\mathrm{p}}\right)}, \\
T_{2}^{\prime \prime}=v \xi_{\mathrm{p}} N^{\prime \prime}-\left(\frac{\mu_{1} T_{2, b}}{1+\mu_{2} T_{2, b}}+1\right) T_{1}^{\prime \prime}+1, \\
A_{\mathrm{p}}^{\prime \prime}=-\left(A_{\mathrm{p}, b}\right)^{2}\left(T_{1}^{\prime \prime}+T_{2}^{\prime \prime}\right) / \xi_{\mathrm{p}} .
\end{gathered}
$$

In both cases a complete elimination of the suppressed $\mathrm{T}$-cell population is thus prevented.

\section{Parameter Choice}

During VIT, the immune system has to deal with single allergen injections rather than with a constant allergen supply. With respect to the short duration of the injections, the rate at which allergen peptide is presented by APCs is approximated by

$$
\xi_{\mathrm{p}}(t)=D_{\mathrm{p}} \delta(t),
$$

where $\delta(t)$ is the Dirac delta function and $D_{\mathrm{p}}$ is the allergen peptide dose which is proportional to the administered allergen dose. In the following, the choice of the parameters of the T-cell model is elucidated.

Proliferation factor $v$. The dynamics of the system is not sensitive to this parameter. If $v$ is transformed to $v_{\text {new }}=f v$, the equations remain unchanged when $A_{\mathrm{p}}$, and $\xi_{\mathrm{p}}(t)$ are re-scaled as follows: $A_{\mathrm{p}}^{\text {new }}=f A_{\mathrm{p}}$ and $D_{\mathrm{p}}^{\text {new }}(t)=$ $f D_{\mathrm{p}}(t)$. For our simulation this parameter was set to be 8 .

Production rate of naive cells $\alpha$. The usual, relatively high allergen dose of an insect sting or an injection administered during the maintenance phase of the therapy is set to the order of 1 . The subsequent response should lead to an elimination of the allergen. Simulations have shown that a minimal $\alpha$ of about 5 is required for a sufficiently fast elimination of an allergen dose of $D_{\mathrm{p}}=1$. For our simulations a value of $\alpha=10$ has been used.

Cytokine background $c$. The small cytokine background originating from other immunological processes is assumed to be constant and has been chosen as $c=10^{-4}$. 

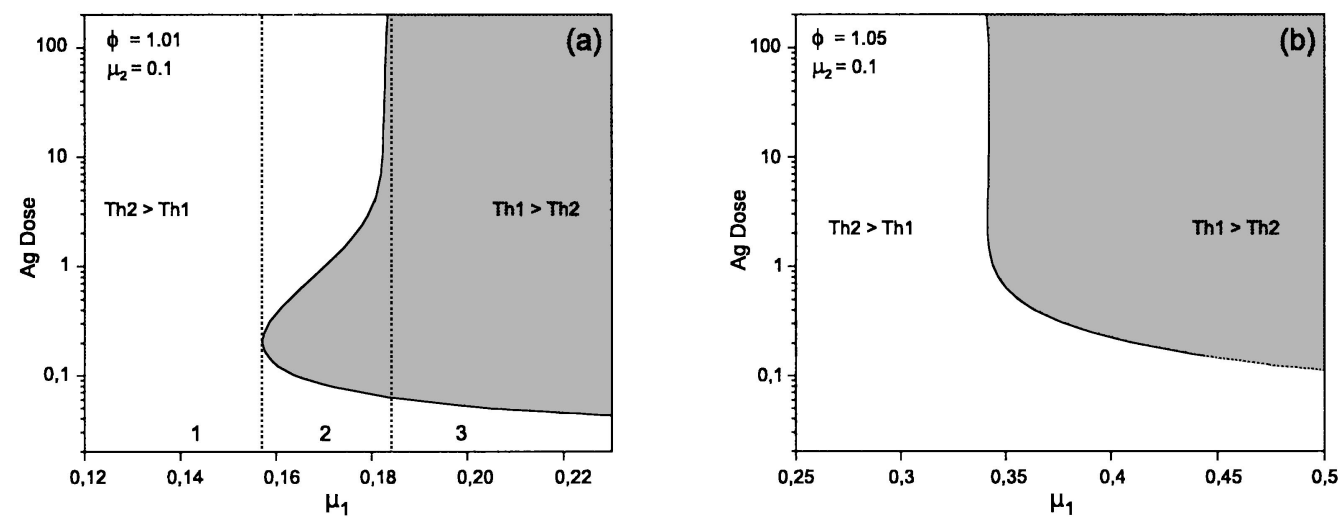

FIGURE 2 Type of response (Th1 or Th2) as a function of the allergen dose and the parameter $\mu_{1}$ for fixed $\phi$ and $\mu_{2}$. The regions, where the response is Th1 dominated is shadowed grey.

The parameters $\phi, \mu_{1}$ and $\mu_{2}$. The decisive parameters determining the qualitative behaviour of the system are $\mu_{1}$ and $\mu_{2}$ measuring the efficiency of the cross-suppression and $\phi$ controlling the balance of the autocrine effects. The Th1-Th2 regulation is conceived as a competition between autocrine and cross-suppressive effects mediated by the cytokines. For small T-cell concentrations, as is the case for small allergen doses, the cross-suppression is negligible, and the equations for $T_{1}$ and $T_{2}$ can be written as

$$
\begin{gathered}
\frac{\mathrm{d} T_{1}}{\mathrm{~d} t}=-T_{1}+v N A_{\mathrm{p}}\left(T_{1}+c\right), \\
\frac{\mathrm{d} T_{2}}{\mathrm{~d} t}=-T_{2}+v \phi N A_{\mathrm{p}}\left(T_{2}+c\right) .
\end{gathered}
$$

Consequently, for small allergen doses the parameter $\phi$ determines the dominant T-cell population. At high concentrations of the allergen, however, the crosssuppressive effects represented by $\mu_{1}$ and $\mu_{2}$ become important. Since the maximum suppression should be of the order of $1 / 10$ and as T-cell concentrations reach in response to an allergen dose of $D_{\mathrm{p}}=1$ values of $\sim 50, \mu_{1}$ and $\mu_{2}$ should be in the range of $0.1-1$.

When the model first was developed, there have been experimental indications that high doses of allergen would select for Th2 cells whereas low doses would favour a Th1 response (Parish and Liew, 1972; Bancroft et al., 1994; Bretscher et al., 1992), which was implemented in the model by setting the parameter $\phi<1$ and $\mu_{1}<\mu_{2}$. The first encounter with a high dose of antigen (first insect sting) would thus result in a Th2 response. The switch from Th2 to Th1 is then attained by the small increasing doses initiating the therapy for conventional protocols (Behn et al., 2001).

However, the rush and ultra-rush protocol reach the high maintenance dose much faster with an initiation phase as short as $3.5 \mathrm{~h}$ (ultra-rush) (Birnbaum, 1998). The T-cell dynamics on the other hand have a much longer time scale (Lanzavecchia and Sallusto, 2000). In addition, recent findings indicate that high antigen doses favour a Th1 response and low doses Th2 (Ruedl et al., 2000;
Secrist et al., 1995; Grakoui et al., 1999), implying that the Th2-Th1 switch is achieved during the second part of the therapy due to the long-term administration of the high allergen doses.

Reviewing the literature on the controversial subject of the dose dependency of T-helper differentiation, it is noticeable that experiments leading to the conclusion high doses favour Th2 and low doses favour Th1 responses dealt, with proliferating antigen (Parish and Liew, 1972; Bancroft et al., 1994; Bretscher et al., 1992) whereas experiments yielding the opposite result dealt with nonproliferating antigen or peptide (Ruedl et al., 2000; Secrist et al., 1995; Grakoui et al., 1999), as used for VIT.

To achieve the observed dose dependency in the model, $\phi>1$ is a necessary condition as has been explained above. Shown in Fig. 2a and b is the dose dependency of the response of the naïve T-cell system for fixed values of $\phi$ and $\mu_{2}$ as a function of $\mu_{1}$. Setting $\phi>1$ provides a Th2 response at low allergen doses for all values of $\mu_{1}$. However, to achieve Th1 responses at high allergen doses $\mu_{1}$ has to surpass a certain threshold, below which only Th2 responses are possible (Fig. 2a, region 1). For small values of $\phi$, there exists a parameter range in which Th2 responses are favoured at very low and again at very high doses of allergen whereas medium to high concentrations favour Th1 responses (Fig. 2, region 2). This phenomenon has also been observed experimentally by Hosken $e t$ al. (1995) using naïve cells. For higher values of $\mu_{1}$ the response to very high doses turns from Th2 to Th1 dominated (Fig. 2a, region 3). Increasing $\phi$ reduces the region 2 of Fig. 2a further and further until it vanishes at $\phi \sim 1.05$ (Fig. 2b).

In general, for every $\phi>1$ and a fixed $\mu_{2}$, there exists a minimal $\mu_{1}$ above which injections of high allergen doses result in Th1 responses and injections of low doses in Th2 responses. For our simulations these parameters were chosen as follows: $\phi=1.02, \mu_{1}=0.2$ and $\mu_{2}=0.1$.

\section{Dynamical Separatrix}

In the following, we analyse the response of the system to single high-dose allergen injections as applied during the 

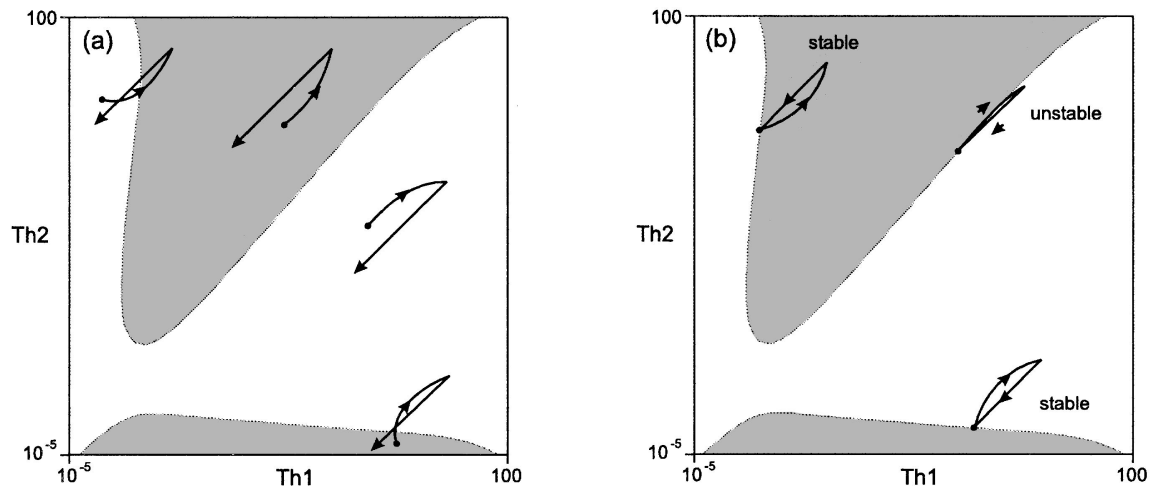

FIGURE 3 (a) The $T_{1}-T_{2}$ plane is divided by the separatrix in regions in which an injection of $D_{\mathrm{p}}=1$ will either improve the ratio $T_{1} / T_{2}$ (white) or impair it (grey). All trajectories start with an injection of $D_{\mathrm{p}}=1$ (dot) and have in common that after the proliferation phase (when $A_{\mathrm{p}}$ has been removed) Th1- and Th2-cells decay exponentially with a constant $T_{1} / T_{2}$ ratio. (b) The non-autonomous system driven by periodically repeated injections exhibits new attractors whose locations depend on the period of injection.

maintenance phase of the therapy. Whether such highdose injections improve, which is desired, or impair the ratio $T_{1} / T_{2}$, depends on the initial values, $T_{1}^{0}$ and $T_{2}^{0}$. In this context, we define the dynamical separatrix as the set of points $\left(T_{1}^{0}, T_{2}^{0}\right)$ for which a single injection of $D_{\mathrm{p}}=1$ does not alter the ratio $T_{1} / T_{2}$. This separatrix parts in the plane of initial conditions $\left(T_{1} / T_{2}\right)$ the region in which an injection of $D_{\mathrm{p}}=1$ will improve the ratio $T_{1} / T_{2}$ from a region, in which such an injection will impair the ratio $T_{1} / T_{2}$ (see Fig. 3a). In the grey-coloured region of Fig. 3a, a single highdose allergen injection will cause an impairment of the original ratio $T_{1} / T_{2}$, whereas in the white region this ratio will improve as is illustrated by characteristic trajectories.

Starting from a point on the separatrix, the trajectory will eventually recross the initial point in the $\left(T_{1}, T_{2}\right)$ plane after a certain time interval $\Delta t$. If the allergen is injected repeatedly with this period $\Delta t$, this non-autonomous system exhibits a periodic behaviour. In Fig. 3b, three cyclic trajectories corresponding to the same period of injection are shown. From Fig. 3a and b, it is evident that the periodically driven non-autonomous system exhibits new attractors that are fixed points of the stroboscopic map. The locations of the attractors is a function of the period of injection $\Delta t$. Whether the system is driven to the Th1- or Th2-cell dominated attractor depends on the initial conditions. Even if the number of injections is not sufficient to reach the attractor, the system will move towards it.

The following remark is in order: concentrations of Tcells cannot become arbitrarily small and the formation of long-lived memory cells will also stabilise the size of a T-cell clone at a certain level. Since during a normal immune response a single T-cell may expand to a clone of $\sim 10^{4}$ cells (Abbas et al., 2000), only T-cell concentrations in the range from $\sim 10^{-3}$ to 100 in dimensionless units have been considered in the following simulations.

\section{Mast Cell/basophil Desensitisation}

In Fig. 4 a simplified scheme of mast cell desensitisation is presented. Mast cells and basophils express substantial amounts of high-affinity $\operatorname{IgE}$ receptors (FceRI). The interaction of serum $\operatorname{IgE}$ with $\mathrm{Fc} \in \mathrm{RI}$ is of high affinity $\left(K_{\mathrm{d}}=10^{-9}-10^{-10} \mathrm{M}\right)$ creating long-lived antigenspecific IgE-Fc $\in$ RI units (Keown et al., 1998). Mast

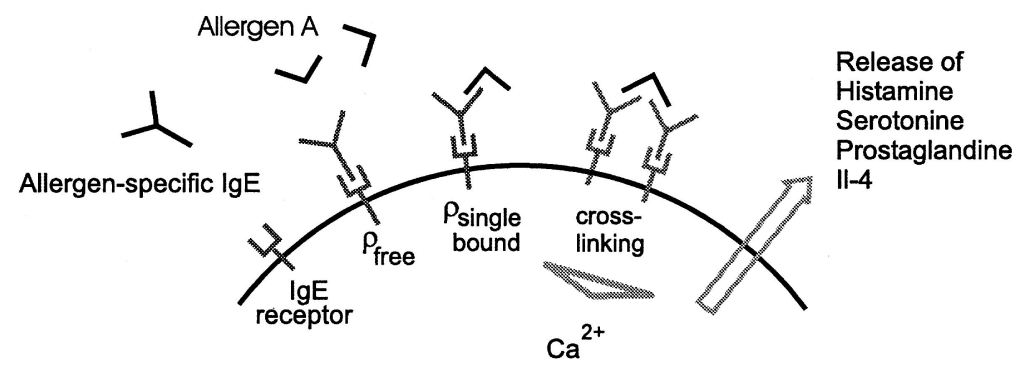

MAST CELL

FIGURE 4 Simplified scheme of IgE-mediated hypersensitivity. Receptors on the mast cell surface bind antigen specific IgE antibodies creating specific IgE-Fc $\in$ RI units of density $\rho_{\mathrm{f}}$. The binding of antigen to such units results in single antigen-IgE-Fc $\in$ RI complexes of density $\rho_{\mathrm{s}}$. The cross-linking of these complexes with adjacent free IgE units triggers a cascade of signalling events that lead to the release of inflammatory mediators. 

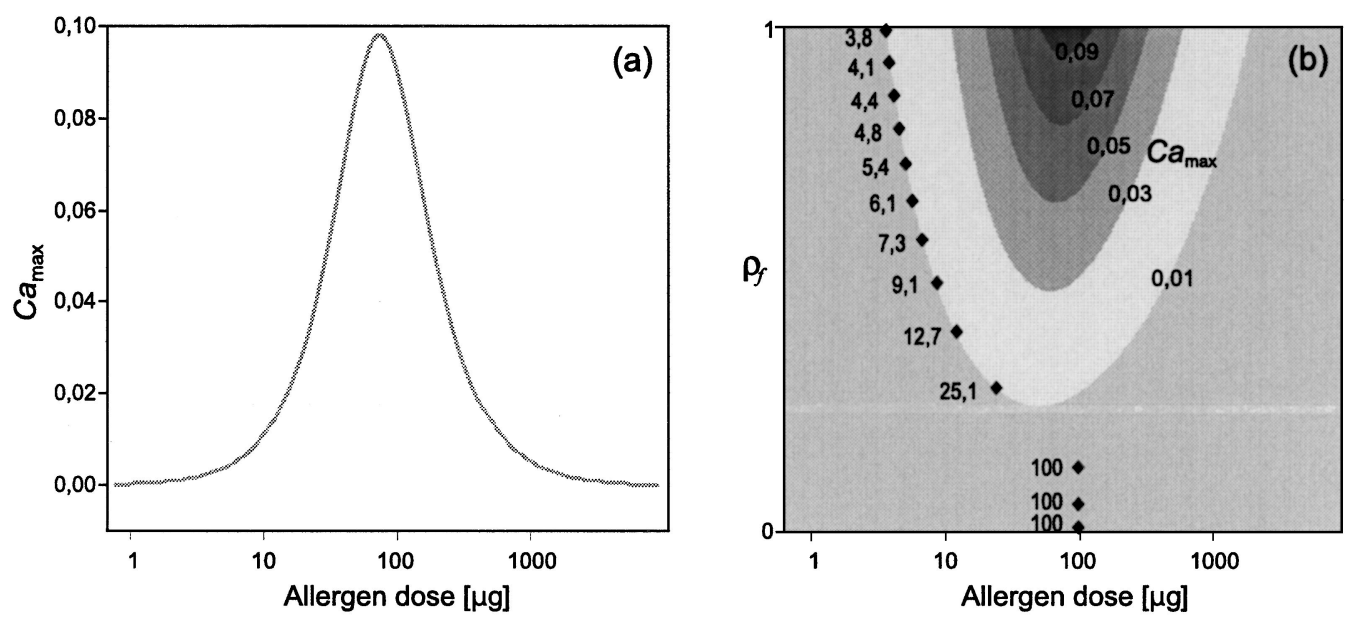

FIGURE 5 (a) The maximum $\mathrm{Ca}^{2+}$ signal as a function of the allergen dose $D$. The decrease of the $\mathrm{Ca}^{2+}$ signal at high allergen doses is caused by the fast formation of single allergen IgE-FceRI complexes using up the majority of unoccupied IgE which limits subsequent cross-linking. (b) The maximum $\mathrm{Ca}^{2+}$ rise as a function of $\rho_{\mathrm{f}}^{0}$ and $D$ is represented by isoclines. Starting at $\rho_{\mathrm{f}}^{0}=1$ the first injection dose leading to a maximum Ca-response of 0.01 is $3.8 \mu \mathrm{g}$. This dose reduces $\rho_{\mathrm{f}}$ by $\Delta \rho_{\mathrm{f}}$ as given in Eq. (37). The new value of $\rho_{\mathrm{f}}$ allows for a dose of $4.1 \mu \mathrm{g}$ and so forth.

cells and basophils respond to antigenic cross-linking of receptors through a cascade of events. The intracellular calcium concentration rises within seconds (Beaven et al., 1984), serotonin and histamine is released from cytoplasmatic secretory granules within minutes (Barsumian et al., 1981), and various prostaglandins and cytokines (i.e. IL-4) are produced within hours (Bradding et al., 1992; Igarashi et al., 1993; Plaut et al., 1989). A correlation between the number of crosslinks and subsequent mediator release has been observed (Chabay and DeLisi, 1980). The histamine release as a result of receptor cross-linking has been modelled by other authors before with different approaches and focuses (Dembo and Goldstein, 1980; Hlavacek et al., 1999; Wofsy et al., 1978). A goal of these studies has been the quantitative analysis of interactions between multivalent ligands and FceRI.

We hypothesise that the successive injection of increasing doses of allergen in the initial phase of the therapy leads to a gradual depletion of specific IgE on the mast cell/basophil surface. Since we are dealing with specific desensitisation the density of free allergen specific IgE-Fc $\epsilon$ RI units $\left(\hat{\rho}_{\mathrm{f}}\right)$ on the mast cell/basophil surface is a crucial quantity. Given that the binding of IgE antibodies to FceRI is independent of their specificity, the density of specific IgE-FceRI units is proportional to the ratio of the specific $\operatorname{IgE}$ titer to the total $\mathrm{IgE}$ titer

$$
\hat{\rho}_{\mathrm{f}} \sim \frac{c_{\mathrm{IgE}}^{\text {specific }}}{c_{\mathrm{IgE}}^{\text {total }}}
$$

For the sake of simplicity we consider the binding of a bivalent antigen to cell surface bound $\operatorname{IgE}$. The following equations describe the dynamics of the density of specific IgE-Fce $\in$ R units $\hat{\rho}_{\mathrm{f}}$, the density of single allergen-IgE-Fc $\epsilon$ RI complexes $\hat{\rho}_{\mathrm{s}}$ resulting from the binding of allergen to an IgE-FceRI unit, the serum concentration of allergen $\hat{A}$, and the intracellular $\mathrm{Ca}^{2+}$ concentration $\hat{C} a$

$$
\begin{gathered}
\frac{\mathrm{d} \hat{p}_{\mathrm{f}}}{\mathrm{d} t}=-\alpha \hat{A} \hat{\rho}_{\mathrm{f}}-\beta \hat{\rho}_{\mathrm{f}} \hat{\rho}_{\mathrm{s}}, \\
\frac{\mathrm{d} \hat{p}_{\mathrm{s}}}{\mathrm{d} t}=\alpha \hat{A} \hat{\rho}_{\mathrm{f}}-\beta \hat{\rho}_{\mathrm{f}} \hat{\rho}_{s}, \\
\frac{\mathrm{d} \hat{A}}{\mathrm{~d} t}=-\epsilon \hat{A} \hat{\rho}_{\mathrm{f}}-\gamma \hat{A}+\omega(t), \\
\frac{\mathrm{d} \hat{C} a}{\mathrm{~d} t}=\chi \hat{\rho}_{\mathrm{f}} \hat{\rho}_{\mathrm{s}}-\delta \hat{C} a .
\end{gathered}
$$

Equations (22) and (23) take into account that free IgEFceRI units vanish by either forming complexes with allergen thus creating single allergen-IgE-FceRI complexes $\left(-\alpha \hat{A} \hat{\rho}_{\mathrm{f}}\right)$ or by cross-linking to allergen already bound to another IgE-FceRI unit $\left(-\beta \hat{\rho}_{\mathrm{f}} \hat{\rho}_{\mathrm{s}}\right)$. The expression of new $\mathrm{IgE-Fc \epsilon RI}$ receptor units on the cell surface has been assumed to take long compared to the desensitisation process and has therefore been neglected. Equation (24) describes how an allergen enters the system at a rate $\omega(t)$ and is eliminated by binding to surface $\operatorname{IgE}\left(-\epsilon \hat{A} \hat{\rho}_{\mathrm{f}}\right)$ and to serum antibodies and different types of APCs which are accounted by $-\gamma \hat{A}$. Finally, Eq. (25) describes how intracellular $\mathrm{Ca}^{2+}$ is raised in proportion to the number of cross-links formed $\left(\chi \hat{\rho}_{\mathrm{f}} \hat{\rho}_{S}\right)$ and is then removed by sequestration into the mitochondria and by extrusion to the exterior $(-\delta \hat{C} a)$.

Measuring the time in units of $1 / \delta$ and re-scaling the variables as

$$
\rho_{\mathrm{f}}=\frac{\beta}{\delta} \hat{\rho}_{\mathrm{f}}, \quad \rho_{\mathrm{s}}=\frac{\beta}{\delta} \hat{\rho}_{\mathrm{s}}, \quad A=\frac{\alpha}{\delta} \hat{A}, \quad C a=\frac{\beta^{2}}{\chi \delta} \hat{C} a
$$


TABLE I Examples of three different standard VIT protocols according to Heppt et al. (1998). Vertical dots indicate a dose repetition every 4 weeks over a period of 3-5 years. In the last column, a theoretical protocol minimising the mast cell/basophil response during the initial phase is given (see also Figs. 5b and 6d)

\begin{tabular}{|c|c|c|c|c|c|}
\hline \multirow[b]{2}{*}{ Day } & \multirow[b]{2}{*}{ Hour } & \multicolumn{4}{|c|}{ Allergen dose $(\mu \mathrm{g})$} \\
\hline & & Conventional & Rush & Ultra-rush & Optimised \\
\hline \multirow[t]{6}{*}{1} & 0 & 0.01 & 0.01 & 0.1 & 3.8 \\
\hline & 0.5 & & 0.1 & 1 & 4.1 \\
\hline & 1 & 0.1 & 1 & 10 & 4.4 \\
\hline & 1.5 & & 2 & 20 & 4.8 \\
\hline & 2.5 & & & 30 & 5.4 \\
\hline & 3.5 & & & 50 & 6.1 \\
\hline \multirow[t]{4}{*}{2} & 0 & & 4 & & 7.3 \\
\hline & 1 & & 8 & & 9.1 \\
\hline & 2 & & 10 & & 12.7 \\
\hline & 3 & & 20 & & 25.1 \\
\hline \multirow[t]{4}{*}{3} & 0 & & 40 & & \\
\hline & 1 & & 60 & & \\
\hline & 2 & & 80 & & \\
\hline & 3 & & & & \\
\hline 4 & & & 100 & & 100 \\
\hline \multirow[t]{3}{*}{8} & 0 & 1 & 100 & 50 & 100 \\
\hline & 0.5 & & & 50 & \\
\hline & 1 & 2 & & & \\
\hline \multirow{2}{*}{15} & 0 & 4 & 100 & & 100 \\
\hline & 1 & 8 & & & \\
\hline \multirow[t]{2}{*}{22} & 0 & 10 & & 100 & \\
\hline & 1 & 20 & & & \\
\hline 29 & & 40 & 100 & & 100 \\
\hline 36 & & 60 & & & \\
\hline 43 & & 80 & 100 & & 100 \\
\hline 50 & & 100 & & 100 & \\
\hline 57 & & 100 & & & \\
\hline 71 & & 100 & 100 & 100 & 100 \\
\hline$\vdots$ & & $\vdots$ & $\vdots$ & : & \\
\hline
\end{tabular}

leads to the new set of equations

$$
\begin{gathered}
\frac{\mathrm{d} \rho_{\mathrm{f}}}{\mathrm{d} t}=-A \rho_{\mathrm{f}}-\rho_{\mathrm{f}} \rho_{\mathrm{s}}, \\
\frac{\mathrm{d} \rho_{\mathrm{s}}}{\mathrm{d} t}=-A \rho_{\mathrm{f}}-\rho_{\mathrm{f}} \rho_{\mathrm{s}}, \\
\frac{\mathrm{d} A}{\mathrm{~d} t}=-\tilde{\beta} A \rho_{\mathrm{f}}-\tilde{\gamma} A+\xi(t), \\
\frac{\mathrm{d} C a}{\mathrm{~d} t}=\rho_{\mathrm{f}} \rho_{\mathrm{s}}-C a .
\end{gathered}
$$

The new, dimensionless parameters $\tilde{\beta}, \tilde{\gamma}$, and $\xi(t)$ are related to the old ones by

$$
\tilde{\beta}=\frac{\epsilon}{\beta}, \quad \tilde{\gamma}=\frac{\gamma}{\delta}, \quad \xi(t)=\frac{\alpha}{\delta^{2}} \omega(t) .
$$

The parameters $\tilde{\beta}$ and $\tilde{\gamma}$ determine the efficiency of elimination of the allergen by binding to surface $\operatorname{IgE}(\tilde{\beta})$ and through other pathways $(\tilde{\gamma})$. Variations in both parameters do not change the qualitative behaviour of the system. $\xi(t)$ is the rate at which antigen enters the system. For the numerical simulations, the parameters have been chosen as $\tilde{\beta}=\tilde{\gamma}=1$.

A typical dose-response curve which represents the highest rise in $\mathrm{Ca}^{2+}$ as a function of the administered allergen dose is shown in Fig. 5a. The decrease of the $\mathrm{Ca}^{2+}$ signal at very high allergen doses is caused by the fast formation of single allergen-IgE-F $\epsilon$ RI complexes using up the majority of unoccupied $\operatorname{IgE}$ which limits subsequent cross-linking. A dose of $100 \mu \mathrm{g}$ has been assumed to correspond to the maximum response stimulation.

\section{Desensitisation}

For $\xi(t)=0$ the system remains in its initial state with $\left(\rho_{\mathrm{f}}, \rho_{\mathrm{s}}, A, C a\right)=\left(\rho_{\mathrm{f}}^{0}, 0,0,0\right)$. A constant allergen supply $\xi(t)=\xi$ on the other hand would lead to a cross-linking of all available $\operatorname{IgE}\left(\rho_{\mathrm{f}} \rightarrow 0\right)$ and would drive the system in the state $(0,0,0, \xi / \tilde{\gamma})$. More interesting in the context of a therapy is the response of the system to single allergen injections. Again we approximate the allergen injection rate by

$$
\xi(t)=D \delta(t)
$$

where $D$ is the administered allergen dose. The rise in $\mathrm{Ca}^{2+}$ is a function of both the amount of the injected allergen $D$ and the initial density of free surface $\operatorname{IgE} \rho_{\mathrm{f}}^{0}$.

An allergen dose $D$ will reduce $\rho_{\mathrm{f}}$ by a certain amount $\Delta \rho_{\mathrm{f}}$. If this dose is small compared to $\rho_{\mathrm{f}}$, it is possible to obtain an analytical approximation for $\Delta \rho_{\mathrm{f}}$. Since for small doses the formation of the intermediate single allergenIgE-complexes $\rho_{\mathrm{s}}$ can be neglected, the equation for $\rho_{\mathrm{f}}$ becomes

$$
\frac{\mathrm{d} \rho_{\mathrm{f}}}{\mathrm{d} t}=-2 A \rho_{\mathrm{f}} .
$$

To determine $\Delta \rho_{\mathrm{f}}$, we only need the equations for $\rho_{\mathrm{f}}$ and $A$, which lead to

$$
\frac{\mathrm{d} A}{\mathrm{~d} \rho_{\mathrm{f}}}=\frac{\tilde{\beta}}{2}+\frac{\tilde{\gamma}}{2 \rho_{\mathrm{f}}} .
$$

Integration with initial conditions $A(0)=D, \rho_{\mathrm{f}}(0)=\rho_{\mathrm{f}}^{0}$ yields

$$
\mathrm{e}^{2(A-D) / \tilde{\gamma}}=\rho_{\mathrm{f}} / \rho_{\mathrm{f}}^{0} \mathrm{e}^{\tilde{\beta}\left(\rho_{\mathrm{f}}-\rho_{\mathrm{f}}^{0}\right) / \tilde{\gamma}} .
$$

We are interested in the value of $\rho_{\mathrm{f}}$ after the allergen has been eliminated $(A \rightarrow 0)$.

Expanding the exponential function on the right side yields

$$
\rho_{\mathrm{f}}^{0} \mathrm{e}^{-(2 / \tilde{\gamma}) D}=\rho_{\mathrm{f}}\left[1+\frac{\tilde{\beta}}{\tilde{\gamma}}\left(\rho_{\mathrm{f}}-\rho_{\mathrm{f}}^{0}\right)\right],
$$

which can be solved for $\rho_{\mathrm{f}}$. Thus, we obtain that an injection of $D$ reduces $\rho_{\mathrm{f}}$ by

$$
\begin{aligned}
\Delta \rho_{\mathrm{f}}= & \rho_{\mathrm{f}}^{0}-\rho_{\mathrm{f}} \\
= & \frac{1}{2}\left(\rho_{\mathrm{f}}^{0}+\frac{\tilde{\gamma}}{\tilde{\beta}}\right) \\
& -\sqrt{\frac{1}{4}\left(\rho_{\mathrm{f}}^{0}-\frac{\tilde{\gamma}}{\tilde{\beta}}\right)^{2}+\frac{\tilde{\gamma}}{\tilde{\beta}} \rho_{\mathrm{f}}^{0} \mathrm{e}^{-(2 / \tilde{\gamma}) D} .}
\end{aligned}
$$



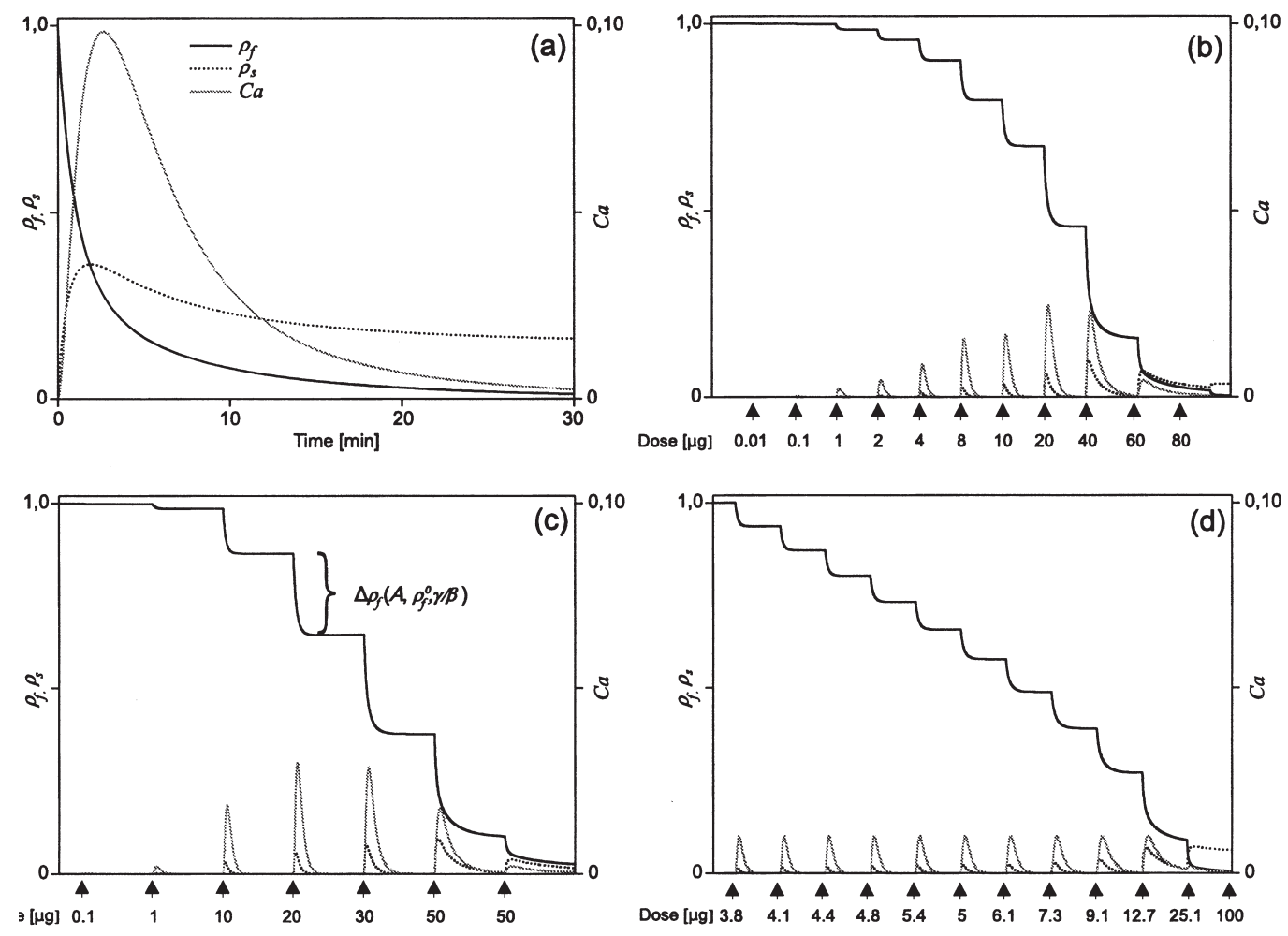

FIGURE 6 Concentrations of $\rho_{\mathrm{f}}, \rho_{\mathrm{s}}$ and $\mathrm{Ca}$ in response to allergen injections as a function of time. (a) Response to a single injection of a dose, which provokes the maximum possible response. Dose sequences according to Conventional/rush protocol (b), Ultra-rush protocol (c) and an optimised protocol (d). For reasons of clarity, in these simulations injections were made at $1 / 2 \mathrm{~h}$ intervals. This is justified as already after this time $\rho_{\mathrm{f}}$ has been reduced by $\Delta \rho_{\mathrm{f}}$ and the concentrations of $\rho_{\mathrm{s}}, A$ and $\mathrm{Ca}$ have practically reached zero baseline so that a prolongation of the interval does not change the response to the subsequent injection.

In the context of a therapy, the maximum rise in $\mathrm{Ca}^{2+}$ in response to the injected allergen doses should not exceed a certain threshold in order to prevent systemic reactions in the patient. Therefore, it is necessary to know the highest allergen dose that can be administered without causing the $\mathrm{Ca}^{2+}$ concentration to pass the threshold.

The isoclines in Fig. 5b represent pairs of values $\left(\rho_{\mathrm{f}}^{0}, D\right)$ resulting in the same maximum calcium rise. Hence for a given threshold of $\mathrm{Ca}_{\max }^{2+}$, an optimal protocol would follow such an isocline. To illustrate this concept, let us consider a system with $\rho_{\mathrm{f}}^{0}=1, \tilde{\beta}=\tilde{\gamma}=$ 1 , the max. $\mathrm{Ca}^{2+}$ should not exceed $1 / 10$ of a maximum response. Starting at $\rho_{\mathrm{f}}^{0}=1$ the first injection dose resulting in a maximum $\mathrm{Ca}^{2+}$-response of 0.01 is $3.8 \mu \mathrm{g}$. This dose reduces $\rho_{\mathrm{f}}$ by $\Delta \rho_{\mathrm{f}}$ as given in Eq. (37). The new, reduced value of $\rho_{\mathrm{f}}$ allows for a higher dose of $4.1 \mu \mathrm{g}$ and so forth.

After reaching the minimum point of the isocline, any allergen dose will be tolerated, since most of the specific IgE has been cross-linked and it is now possible to administer the high allergen doses necessary for the Th2-Th1 switch. The thus optimised protocol is listed in Table I. It should be noted that such a protocol depends of course on $\rho_{\mathrm{f}}^{0}$, the parameters $\tilde{\beta}$ and $\tilde{\gamma}$ as well as the threshold level for $\mathrm{Ca}_{\max }^{2+}$ and is therefore subject to individual changes.

\section{VENOM IMMUNOTHERAPY}

The principle of VIT is the subcutaneous injection of increasing doses of venom up to a maintenance dose of about $100 \mu \mathrm{g}$. Several protocols with varying intervals between injections have been established (see Table I). The time required to reach the maintenance phase of the therapy varies from several weeks (conventional protocol), over 3-5 days (rush protocol) to $3.5 \mathrm{~h}$ (ultra-rush protocol). Studies on rush and ultra-rush protocols indicate that protection is provided rapidly and that these protocols are not less safe than the conventional (Birnbaum et al., 1993; Brehler et al., 2000; Skribic et al., 1996). In this chapter, the different therapy protocols are investigated in the frame of the previously formulated mathematical models of Th1/Th2-regulation and mast cell/basophil desensitisation.

\section{Mast Cell/Basophil Desensitisation}

The purpose of the slowly increasing doses is to keep the corresponding $\mathrm{Ca}^{2+}$ rise in the mast cells/basophils and therewith the histamine release on a moderate level. The time between successive injections must allow the calcium concentration to reach baseline again which takes approximately 15-30 min (Beaven et al., 1984). This 

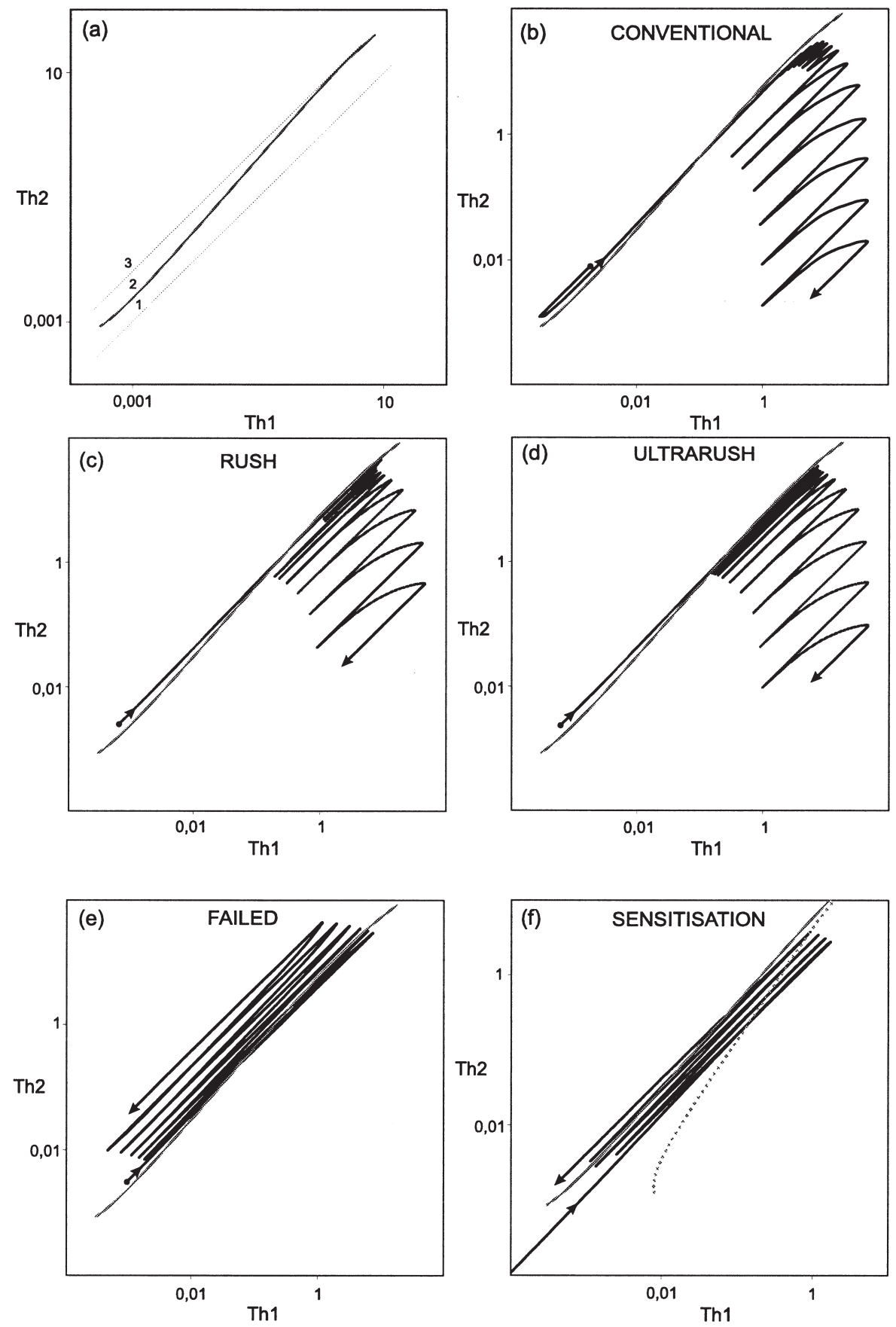

FIGURE 7 (a) The three possible regions of initial conditions. (b) Conventional, (c) Rush and (d) Ultra-rush protocol starting from a state in region 2 achieving the desired Th2-Th1 switch. (e) Therapy failed because the intervals between injections were too long (in this case $>2$ months). (f) Sensitisation by 4 injections of $D_{\mathrm{p}}=0.1$. The dotted line represents the separatrix for $D_{\mathrm{p}}=0.1$, so that all injections take place in the region where they impair the $T_{1} / T_{2}$ ratio.

condition is fulfilled by all standard protocols, examples of which are given in Table I.

Figures $6 \mathrm{~b}$ and $\mathrm{c}$ show the concentrations of $\rho_{\mathrm{f}}, \rho_{\mathrm{s}}$ and $\mathrm{Ca}$ in response to allergen injections as a function of time for the three different protocols. The number of free specific IgE-Fc $\in$ RI units is reduced gradually to almost zero so that the subsequently administered high allergen doses cannot cause further histamine release. The conventional and rush protocol differ only in the time intervals between injections during initial phase, but not in the administered doses. Therefore, for mast cell/basophil desensitisation both protocols display a similar behaviour in our model. However, in ultra-rush therapy the doses are increased more rapidly thus giving rise to slightly larger $\mathrm{Ca}^{2+}$ peaks. Nonetheless, the magnitude of the $\mathrm{Ca}^{2+}$ signal in all protocols is strongly reduced compared to a single injection provoking the maximum response as shown in Fig. 6a.

In Fig. 6d is shown an optimised protocol which minimises for a given number of injections (in the present 


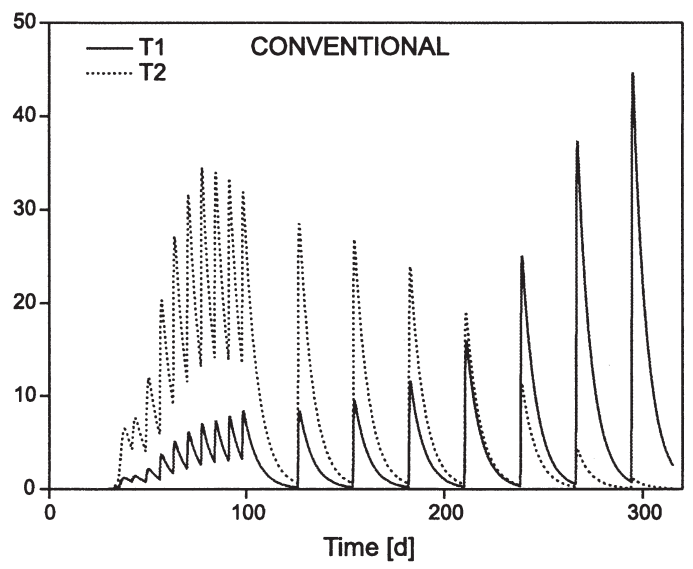

FIGURE 8 Conventional therapy protocol. With the beginning of the administration of the high doses of allergen, the Th1-cell population gradually exceeds the population of Th2-cells.

case 10) the maximum $\mathrm{Ca}$ signal (see also Fig. 5b). Examples for conventional: rush and ultra-rush protocols are given in Table I together with an optimised protocol.

\section{Th1/Th2 Switch}

As discussed above, Th1 cells are preferentially stimulated by high antigen doses and high peptide-MHC affinity. Therefore a switch from Th2 to Th1 can be expected in the course of the administration of the high allergen doses.

Assuming that for an allergic individual initially $T_{2}^{0}>$ $T_{1}^{0}$, three regions in the $\left(T_{1} / T_{2}\right)$-plane can be distinguished according to the response to high allergen injections of $D_{\mathrm{p}}=1$ (corresponding to the maintenance dose of $100 \mu \mathrm{g})$, see Fig. 7a:

Region 1: Successive injections of $D_{\mathrm{p}}=1$ will continuously improve the ratio $T_{1} / T_{2}$ independent of the time interval between injections.

Region 2: Even though an injection of $D_{\mathrm{p}}=1$ will impair the ratio $T_{1} / T_{2}$, the trajectory can transiently cross the separatrix. If a further allergen injection takes place while the system is still beyond the separatrix, it is possible to improve the $T_{1} / T_{2}$ ratio. Success or failure of a therapy depend in this case clearly on the schedule of injections.

Region 3: In this case, the Th2-cell dominance is too pronounced such that every injection of allergen will only further impair the $T_{1} / T_{2}$ ratio.

The high rate of success of the therapy suggests that most patients have initial conditions in region 1 and 2. Starting from region 1, the therapy will be successful independently of the intervals between injections.

The time interval between injections plays only then a decisive role when the system is initially in region 2 . If an allergen dose of $D_{\mathrm{p}}=1$ is then injected, the trajectory will cross transiently the separatrix. For a successful therapy, the next allergen injection has to be given while the trajectory is on the other side of the separatrix, where allergen injections will cause improvement of the $T_{1} / T_{2}$ ratio. This time slot clearly depends on the initial conditions again. If the initial state is very close to the separatrix, the trajectory will quickly cross the separatrix and then stay there a long time ( $~ 60-70$ days), before recrossing the separatrix. The further the initial state is apart from the separatrix, the shorter is the time the trajectory will be at the other side of the separatrix, which makes the timing of the subsequent injection more and more crucial. Therefore, shorter intervals between injections at the beginning of the therapy will increase the chance of success. Interestingly, the schedule of the empirical protocols follows already such a strategy by increasing the interval between the $100 \mu \mathrm{g}$ doses from initially one week over two weeks to eventually four weeks. In Fig. 7 b-d, it is shown that starting at an initial state in region 2, all three empirical protocols can achieve the Th2-Th1 switch. Figures 8 and 9 show the concentrations of the allergen and of Th1 and Th2 cells as a function of time for the situations displayed in the previous figure. As expected, the rush and ultra-rush protocols yield almost identical results since the intervals
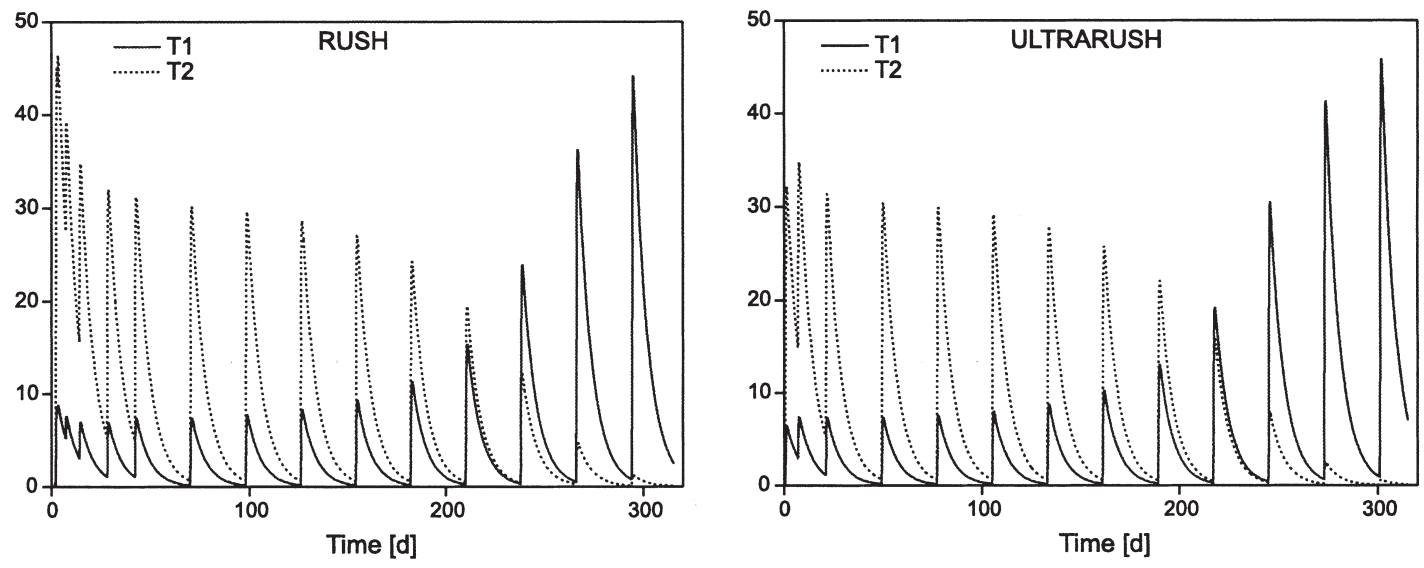

FIGURE 9 Rush and ultra-rush therapy protocols. As expected, the rush and ultra-rush protocols yield almost identical results since the time intervals between the initiation doses are short in comparison with the lifetime of the T-cells. 
between the initiation doses are short in comparison with the lifetime of the T-cells.

If the intervals between injections are too long, therapy may fail to produce a Th2-Th1 switch as shown in Fig. $7 \mathrm{e}$. With an interval of 2 months all injections take place in the region where they impair the $T_{1} / T_{2}$ ratio.

\section{DISCUSSION}

The modelling of Th1-Th2 regulation and mastcell/ basophil desensitisation requires of course simplification of very complex systems. Nevertheless, the analysis and simulations have shown that the models can account for essential features of VIT. The models are able to explain the empirical structure of the protocols and the influence of the timing and the magnitude of the allergen doses on the Tcell regulation and mastcell/basophil desensitisation.

The purpose of these mathematical models is to contribute to the understanding of the related immunological processes and to yield indications for an improved therapy. Looking at the dose-response curve in Fig. 5a, one could conclude that there are two ways for an optimal desensitisation of the mast cells/basophils: a single injection of a very high dose on one hand and the very long-term administration of very low doses or a low-dose infusion of allergen on the other. However, the toxicity of the insect venom rules out the application of such a high dose (equivalent to 100 or 1000 insect stings) which would surely block all membrane $\mathrm{IgE}$ and prevent cross-linking but would also kill even a non-allergic person. On the other hand, the long-term administration of very low and thereby very safe doses would mean a very high number of injections which is also not in the interest of the patient. Therefore, it is important to reach the maintenance dose quickly, but with minimum risk. To arrive at the maintenance dose of $100 \mu \mathrm{g}$ with a given number of injections, in our case 10 , there is only one protocol minimising the maximal $\mathrm{Ca}^{2+}$ signal (see Table I). Such a protocol depends, however, on patient specific parameters, the specific $\operatorname{IgE} /$ total $\operatorname{IgE}$ ratio and the specific $\operatorname{IgG}$ concentration (see Fig. 6d).

The Th2-Th1 switch on the other hand secures the long-term protection of the patients. Analysis of the T-cell model has shown that shorter time intervals at the beginning of the $100 \mu \mathrm{g}$ dose injections enhance the chance of success and do also quicken the shift from Th2Th1. The corresponding reduction of the specific IgE-level leads to a decreased $\rho_{\mathrm{f}} \sim c_{\mathrm{IgE}}^{\text {specific }} / c_{\mathrm{IgE}}^{\text {total }}$ and an enhanced production of specific IgG4 means a bigger $\tilde{\gamma}$ in Eq. (29). Both factors can reduce the $\mathrm{Ca}^{2+}$ response to a given injection and therefore the antigen specific histamine release significantly. From Fig. $7 b-d$, it can also be concluded that in the later part of the therapy, when the trajectory is no longer able to recross the separatrix, the intervals between injections could safely be extended. Only very recently it has been shown that even 3-month intervals in the maintenance phase are both safe and successful (Goldberg and Confino-Cohen, 2001).

The Th2 dominated response in allergic individuals has probably a multicausal origin. First of all there is evidence for genetic factors, which can in some allergic patients account for a Th2 dominated immune response (Ono, 2000). Environmental factors also play a role in the onset of allergic diseases (Parronchi et al., 2000). In addition, it has been shown that allergens present in bee venom induce mast cell and basophil degranulation and stimulate IL-4 production even in the absence of antigen specific IgE (Machado et al., 1996). However, the relevance of cytokines produced by mast cells/basophils in the differentiation process of the T-cells lacks clear experimental evidence and has not been considered in our models so far.

Individual history certainly plays a role in the onset of allergy. In the case of wasp VIT, the maintenance dose is $\sim 10-20$ times higher than that of a normal sting. The amount of venom the insect is able to inject varies also with the age of the insect and with the season. Since the separatrix is a function of the allergen dose, the response of the naïve system depends crucially on the dose of the first allergen contacts. Figure $7 \mathrm{f}$ shows that a sensitisation can be achieved with only three injections of $D_{\mathrm{p}}=0.1$ corresponding to lower dose wasp stings. The dotted line represents the separatrix for $D_{\mathrm{p}}=0.1$. The shift of the separatrix towards Th1 reflects the dose dependency of the T-cell differentiation. This is consistent with the experimental findings of Kolbe et al. (1991), who observed that repeated injections of minute doses of phospholipase $A_{2}(0.1 \mu \mathrm{g} /$ mouse $)$ induce a persisting high level IgE titer, whereas large doses ( $10 \mu \mathrm{g}$ /mouse) induce only low levels of IgE.

Bergmann et al. (2001) modelled T-helper cell differentiation and cross regulation including activation induced cell death (AICD) in the presence of proliferating antigen. Their model, however, features Th2 responses at high and Th1 responses at low antigen doses. Since the nature of the antigen (proliferating vs. non-proliferating) may crucially influence the dose dependency of the Thelper cell differentiation (as discussed in "Parameter choice" section), it would be interesting to investigate whether these differences can be modelled by varying only antigenic proliferation.

Fishman and Segel (1996) formulated a compartment model to describe immunotherapy for pollen allergy (for a review of compartmentalisation, see Kroemer et al., 1993). It is based on the assumption that an antigen introduced to lymph nodes that drain mucosal surfaces induce a predominantly Th2 response whereas the same antigen introduced into non-mucosal lymph nodes will lead to a Th1 response.

In our case of insect venom allergy where the draining lymphatic tissue is the same for an insect sting and the sites of therapeutic injections, the Th1/Th2 switch can be explained in the frame of nonlinear non-autonomous dynamics. 


\section{Acknowledgements}

We wish to thank Dr Vipin Kumar for his valuable help concerning the parameter choice of the T-cell model. J. Richter was supported by the Interdisciplinary Centre for Clinical Research (IZKF) Leipzig.

\section{References}

Abbas, A.K., Murphyand, K.M. and Sher, A. (1996) "Functional diversity of helper T lymphocytes", Nature 383(6603), 787-793.

Abbas, A.K., Lichtman, A.H. and Pober, J.S. (2000) Cellular and Molecular Immunology, 4th Ed. (W B Saunders Co, London).

Agarwal, S. and Rao, A. (1998) "Modulation of chromatin structure regulates cytokine gene expression during $\mathrm{T}$ cell differentiation", Immunity 9(6), 765-775.

Bancroft, A.J., Else, K.J. and Grencis, R.K. (1994) "Low-level infection with Trichuris muris significantly affects the polarization of the CD4 response", Eur. J. Immunol. 24(12), 3113-3118.

Barsumian, E.L., Isersk, C., Petrino, M.G. and Siraganian, R.P. (1981) "IgE induced histamine release from rat, basophilic leukemia cell lines: Isolation of releasing and non-releasing clones", Eur. J. Immunol. 11(4), 317-323.

Beaven, M.A., Rogers, J., Moore, J.P., Hesketh, T.R., Smith, G.A. and Metcalfe, J.C. (1984) "The mechanism of the calcium signal and correlation with histamine release in $2 \mathrm{H} 3$ cells", J. Biol. Chem. 259(11), 7129-7136.

Behn, U., Dambeck, H. and Metzner, G. (2001) "Modeling Th1-Th2 regulation, allergy and hyposensitization", In: Bagnoli, F. and Ruffo, S., eds, Dynamical Modeling in Biotechnology (World Scientific, Singapore), (Lectures presented at the EU Advanced Workshop, Torino, May 27-June 9, 1996), pp 227-244.

Bergmann, C., Hemmen, J.L.V. and Segel, L.A. (2001) "Th1 or Th2: how an appropriate T helper response can be made", Bull. Math. Biol. 63(3), 405-430.

Birnbaum, J. (1998) "Protocole de désensibilisation accéléree venins d'hyménoptères", Med. Hyg. 46, 2405-2410.

Birnbaum, J., Charpin, D. and Vervloet, D. (1993) "Rapid Hymenoptera venom immunotherapy: comparative safety of three protocols", Clin. Exp. Allergy 23(3), 226-230.

Blaser, K., Carballido, J., Faith, A., Crameri, R. and Akdis, C. (1998) "Determinants and mechanisms of human immune responses to bee venom phospholipase A2", Int. Arch. Allergy Immunol. 117(1), 1-10.

Bradding, P., Feather, I.H., Howarth, P.H., Mueller, R., Roberts, J.A., Britten, K., Bew, J.P.A., Hunt, T.C., Okayama, Y., Heusser, C.H., Bullock, G.R., Church, M.K. and Holgate, S.T. (1992) "Interleukin-4 is located TO and released by human mastcells", J. Exp. Med. 176, $1381-1386$.

Brehler, R., Wolf, H., Kuetting, B. and Schnitker, J. (2000) "Safety of a two day ultrarush insect venom immunotherapy protocol in comparison with protocols of longer duration and involving a larger number of injections", J. Allergy Clin. Immunol. 105(6), 1231-1235.

Bretscher, P.A., Wei, G., Menonl, J. and Bielefeld-Ohmann, H. (1992) "Establishment of stable. cell-mediated immunity that makes 'susceptible' mice resistant to Leishmania major", Science 257(5069), 539-542.

Chabay, R. and DeLisi, C. (1980) "Receptor cross-linking and histamine release in basophils", J. Biol. Chem. 255(10), 4628-4635.

Chaturvedi, P., Yu, Q., Southwood, S., Sette, A. and Singh, B. (1996) "Peptide analogs with different, affinities for MHC alter the cytokine profile of T helper cells", Int. Immunol. 8(5), 745-755.

Dembo, M. and Goldstein, B. (1980) "A model of cell activation and desensitization by surface immunoglobin: the case of histamine release from human basophils", Cell 22(1), 59-67.

Fishman, M.A. and Segel, L.A. (1996) "Modeling immunotherapy for allergy", Bull. Math. Biol. 58(6), 1099-1121.

Goldberg, A. and Confino-Cohen, R. (2001) "Maintenance venom immunotherapy administered at 3-month intervals is both safe and efficacious", J. Allergy Clin Immunol. 107(5), 902-906.

Golden, D.B.K., Kagey-Sobotk, A. and Lichtenstein, L.M. (2000) "Survey of patients after discontinuing venom immunotherapy", J. Allergy Clin. Immunol. 105(2), 385-390.

Grakoui, A., Donermeyer, D.L., Kanagawa, O., Murphy, K. and Allen, P.M. (1999) "TCR-independent pathways mediate the effects of antigen dose and altered peptide ligands on Th cell polarization", J. Immunol. 162(4), 1923-1930.

Hamann, D., Hilkens, C.M., Grogan, J.L., Lens, S.M., Kapsenberg, M.L., Yazdanbakhsh, M. and van Lier, R.A. (1996) "CD30 expression does not discriminate between human Th1- and Th2-type T cells", J. Immunol. 156(4), 1387-1391.

Heppt, W., Reuz, H. and Roecken, M., eds, (1998) Allergologie, (Springer, Berlin).

Hlavacek, W.S., Perelson, A.S., Sulzer, B., Bold, J., Paar, J., Gorman, W. and Posner, R.G. (1999) "Quantifying aggregation of IgEFcepsilonRI by multivalent antigen", Biophys. J. 76(5), 2421-2431.

Hosken, N.A., Shibuya, K., Heath, A.W., Murphy, K.M. and O'Garra, A. (1995) "The effect of antigen dose on CD4 $+\mathrm{T}$ helper cell phenotype development in a $\mathrm{T}$ cell receptor-alpha beta-transgenic model", J. Exp. Med. 182(5), 1579-1584.

Hunt, K.J., Valentine, M.D., Sobotka, A.K., Benton, A.W., Amodio, F.J. and Lichtenstein, L.M. (1978) "A controlled trial of immunotherapy in insect hypersensitivity", N. Engl. J. Med. 299(4), 157-161.

Igarashi, Y., Lundgren, J.D., Shelhamer, J.H., Kaliner, M.A. and White, M.V. (1993) "Effects of inhibitors of arachidonic acid metabolism on serotonin release from rat basophilic leukemia cells", Immunopharmocology 25(2), 131-144.

Kapsenberg, M.L., Hilkens, C.M., Wierenga, E.A. and Kalinski, P. (1998) "The role of antigen-presenting cells in the regulation of allergenspecific T cell responses", Curr. Opin. Immunol. 10(6), 607-613.

Keown, M.B., Henry, A.J., Ghirlando, R., Sutton, B.J. and Gould, H.J. (1998) "Thermodynamics of the interaction of human immunoglobulin E with its high affinity receptor Fc epsilon RI", Biochemistry 37(25), 8863-8869.

Kolbe, L., Heusser, C. and Kolsch, E. (1991) "Antigen dose-dependent regulation of B epsilon-memory cell expression", Int. Arch. Allergy Appl. Immunol. 95(2-3), 202-206.

Kroemer, G., Cuende, E. and Martinez, A.C. (1993) "Compartmentalization of the peripheral immune system", Adv. Immunol. 53, 157-216.

Kumar, V., Bhardwaj, V., Soares, L., Alexander, J., Sette, A. and Sercarz, E. (1995) "Major histocompatibility complex binding affinity of an antigenic determinant, is crucial for the differential secretion of interleukin $4 / 5$ or interferon gamma by T cells", Proc. Natl Acad. Sci. USA 92(21), 9510-9514.

Lanzavecchia, A. and Sallusto, F. (2000) "Dynamics of T lymphocyte responses: intermediates, effectors, and memory cells", Science 290(5489), 92-97.

Machado, D.C., Horton, D., Harrop, R., Peachell, P.T. and Helm, B.A. (1996) "Potential allergens stimulate the release of mediators of the allergic response from cells of mast cell lineage in the absence of sensitization with antigen-specific IgE”, Eur. J. Immunol. 26(12), 2972-2980.

McHugh, S.M., Deighton, J., Stewart, A.G., Lachmann, P.J. and Ewan, P.W. (1995) "Bee venom immunotherapy induces a, shift in cytokine responses from a Th-2 to a Th-1 dominant pattern: comparison of rush and conventional immunotherapy", Clin. Exp. Allergy 25(9), $828-838$.

Mosmann, T.R., Cherwinski, H., Bond, M.W., Gieldin, M.A. and Coffmann, R.L. (1986) "Two types of murine helper T cell clones. Definition according to profiles of lymphokine activities and secreted proteins", J. Immunol. 136(7), 2348-2357.

Murphy, K.M., Ouyang, W., Szabo, S.J., Jacobson, N.G., Guler, M.L., Gorham, J.D., Gubler, U. and Murphy, T.L. (1999) "T helper differentiation proceeds through Stat1-dependent, Stat4-dependent and Stat4-independent phases", Curr. Top. Microbiol. Immunol. 238, $13-26$

Murray, J.S. (1998) "How the MHC selects Th1/Th2 immunity", Immunol. Today 19(4), 157-163.

Noon, L. and Cantab, B.C. (1911) "Prophylactic inoculation against hay fever", Lancet 1, 1572-1574.

Odum, N., Bregenholt, S., Eriksen, K.W., Skov, S., Ryder, L.P., Bendtzen, K., Neerven, R.J.V., Svejgaard, A. and Garred, P. (1999) "The CCchemokine receptor 5 (CCR5) is a marker of, but not essential for the development of human Th1 cells", Tissue Antigens 54(6), 572-577.

Ono, S.J. (2000) "Molecular genetics of allergic diseases", Аnnи. Rev. Immunol. 18, 347-366.

Parish, C.R. and Liew, F.Y. (1972) "The relationship between humoral and cell-mediated immunity", Transplant. Rev. 13, 35-66.

Parronchi, P., Brugnolo, F., Sampognaro, S. and Maggi, E. (2000) "Genetic and environmental factors contributing to the onset, of allergic disorders", Int. Arch. Allergy Immunol. 121(1), 2-9. 
Petkova, D., Xaubet, A., Picado, C., Filella, X., Agusti, C., Luburich, P. and Rodriguez-Roisin, R. (2000) "Evaluation of CD30 as a marker for Th2 lymphocytes in bronchoalveolar lavage in interstitial lung diseases", Respir. Med. 94(4), 345-349.

Plaut, M., Pierce, J.H., Watson, C.J., Hanley-Hyde, J., Nordan, R.P. and Paul, W.E. (1989) "Mast cell lines produce lymphokines in response to cross-linkage of FceRI or to calcium ionophores", Nature 339(6219), 64-67.

Reisman, R. (1992) "Venom immunotherapy: 10 years of experience with administration of single venoms and $50 \mathrm{pg}$ maintenance doses", J. Allergy Clin. Immunol. 89(6), 494-498.

Rincon, M. and Flavell, R.A. (1997) "T-cell subsets: transcriptional control in the Th1/Th2 decision", Curr. Biol. 7(11), 729-732.

Romagnani, S. (1991) "Human Th1 and Th2: doubt no more", Immunol. Today 12(8), 256-257.

Romagnani, S. (1993) "Regulatory role of IL-4 and other cytokines on the function and development of human T cell clones", Res. Immunol. Immunobiol. 144(8), 652-658.

Romagnani, S., eds, (1996) "Th1 and Th2 Cells in Health and Disease", Chemical Immunology (Karger, Basel) Vol. 63 of 21.

Romagnani, S. (1997) "The Th1/Th2 paradigm", Immunol. Today 18(6), $263-266$.

Ruedl, C., Bachmann, M.F. and Kopf, M. (2000) "The antigen dose determines $\mathrm{T}$ helper subset development by regulation of CD40 ligand", Eur. J. Immunol. 30(7), 2056-2064.

Schuerwegh, A.J., Cluck, L.S.D., Bridts, C.H. and Stevens, W.J. (2001) "Wasp venom immunotherapy induces a shift from IL-4-producing towards interferon-gamma-producing $\mathrm{CD} 4+$ and $\mathrm{CD} 8+\mathrm{T}$ lymphocytes", Clin. Exp. Allergy 31(5), 740-746.

Secrist, H., DeKruyff, R.H. and Umetsu, D.T. (1995) "Interleukin 4 production by $\mathrm{CD} 4+\mathrm{T}$ cells from allergic individuals is modulated by antigen concentration and antigen-presenting cell type", J. Exp. Med. 181(3), 1081-1089.

Seder, R., Gazzinelli, R., Sher, A. and Paul, W.E. (1993) "Interleukin 12 acts directly on CD4 + T cells to enhance priming for interferon $\gamma$ production and diminishes interleukin 4 inhibition of such priming", Proc. Natl Acad. Sci. USA 90(21), 10188-10192.

Skribic, D., Jutel, M., Fischer, H., Pitarch, D. and Mueller, U. (1996) "Ultrarush-Hyposensibilisierung mit Hymenopterengiften", Allergologie 19(3), 123-129.

Swain, S.L., Weinberg, A.D., English, M. and Huston, G. (1990) "IL-4 directs the development of Th2-like helper effectors", J. Immunol. 145(11), 3796-3806.

Takemoto, S., Kamogawa, Y., Lee, H.J., Kurata, H., Arai, K.I., O'Garra, A., Arai, N. and Miyatake, S. (2000) "Cutting edge: chromatin remodeling at the IL-4/IL-13 intergenic regulatory region for Th2-specific cytokine gene cluster", J. Immunol. $\mathbf{1 6 5}(12), 6687-6691$.

Tari, M.G., Mancino, M., Madonna, F., Buzzoni, L. and Parmiani, S. (1994) "Immunologic evaluation of 24 month course of sublingual immunotherapy", Allergol. Immunopathol. (Madr) 22(5), 209-216.

Wofsy, C., Goldstein, B. and Dembo, M. (1978) "Theory of equilibrium binding of asymmetric bivalent, haptens to cell surface antibody: application to histamine release from basophils", J. Immunol. 121(2), 393-601.

\section{APPENDIX}

\section{Rescaling of the T-cell Model}

To reduce the number of variables, we do not distinguish the different cytokines secreted by Th1-cells denoting all of them by IF, in a similar way we denote the cytokines secreted by Th2-cells by IL. For better understanding, we refrain in the first step from including cytokines coming from other immune processes (later considered as a cytokine background). Thus we model the nonlinear dynamics of Th1-Th2 regulation in the presence of allergen by the following equations for the concentrations per unit volume of naïve cells $(\hat{N})$, Th1- and Th2-cells $\left(\hat{T}_{1}\right.$ and $\left.\hat{T}_{2}\right)$, cytokines IF and IL, and allergen peptide $\left(\hat{A}_{\mathrm{p}}\right)$ presented by APCs:

$$
\begin{gathered}
\frac{\mathrm{d} \hat{N}}{\mathrm{~d} t}=-\gamma \hat{N}+\rho-\beta_{1} \hat{N} \hat{A}_{\mathrm{p}} \mathrm{IF}-\beta_{2} \hat{N} \hat{A}_{\mathrm{p}} \mathrm{IL}, \\
\frac{\mathrm{d} \hat{T}_{1}}{\mathrm{~d} t}=-\gamma \hat{T}_{1}+v \beta_{1} \hat{N} \hat{A}_{\mathrm{p}} \mathrm{IF}, \\
\frac{\mathrm{d} \hat{T}_{2}}{\mathrm{~d} t}=-\gamma \hat{T}_{2}+v \beta_{2} \hat{N} \hat{A}_{\mathrm{p}} \frac{\mathrm{IL}}{1+c_{1} \mathrm{IF}}, \\
\frac{\mathrm{dIF}}{\mathrm{d} t}=-\delta \mathrm{IF}+\alpha_{1} \frac{\hat{T}_{1}}{1+c_{2} \mathrm{IL}}, \\
\frac{\mathrm{dIL}}{\mathrm{d} t}=-\delta \mathrm{IL}+\alpha_{2} \hat{T}_{2}, \\
\frac{\mathrm{d} \hat{A}_{\mathrm{p}}}{\mathrm{d} t}=\varepsilon \omega(t)-\lambda \hat{A}_{\mathrm{p}}\left(\hat{T}_{1}+\hat{T}_{2}\right) .
\end{gathered}
$$

Naïve cells are produced with a rate $\rho$ and decay with the same characteristic time $1 / \gamma$ as the Th1- and Th2-cells. Stimulated naïve cells disappear from the pool of naïve cells; their number is proportional to $\hat{N} \cdot \hat{A}_{\mathrm{p}}$.cytokine, where the last factor mirrors the autocrine effect of the cytokines IF or IL. The parameters $\beta_{1}$ and $\beta_{2}$ allow for differences in the activation of Th1- and Th2-cells by allergen presenting cells. A stimulated naïve cell proliferates and produces in the mean $v$ T-cells. Cytokines decay with a characteristic time $1 / \delta$ which is small compared to $1 / \gamma$; their production rate is proportional to the number of T-cells. The crosssuppression is modelled by factors of the form $1 /(1+$ const-cytokine), which tend to 1 for low concentrations.

Since the cytokines IL secreted from Th2-cells suppress the IF production whereas the cytokines IF secreted from Th1-cells suppress the Th2-proliferation there is an asymmetry in the equations for $\hat{T}_{1}$ and IF on one side and the equations for $\hat{T}_{2}$ and $\mathrm{IL}$ on the other side. Allergen peptide is supplied at a rate proportional to the allergen injection rate $\omega(t)$ and is eliminated proportional to the number of Th1- and Th2-cells.

Adiabatic elimination. Since the life-time of cytokines is short compared to that of T-cells $(1 / \delta \ll 1 / \gamma)$ cytokines relax fast to a quasi-stationary state dictated by the Th1and Th2-cells,

$$
\begin{gathered}
\mathrm{IL}=\frac{\alpha_{2}}{\delta} \hat{T}_{2}, \\
\mathrm{IF}=\alpha_{1} /\left(\delta\left(1+c_{2} \frac{\alpha_{2}}{\delta} \hat{T} 2\right)\right) \hat{T}_{1} .
\end{gathered}
$$

This allows to reduce the number of variables by inserting Eqs. (A.7) and (A.8) into Eqs. (A.1)-(A.3). Measuring the time in units of $1 / \gamma$ and rescaling the variables as

$$
\begin{aligned}
& \hat{N}=\frac{\gamma}{\lambda} N, \quad \hat{T}_{1}=\frac{\gamma}{\lambda} T_{1}, \quad \hat{T}_{2}=\frac{\gamma}{\lambda} T_{2}, \\
& \hat{A}_{\mathrm{p}}=\frac{\lambda \delta}{\alpha_{1} \beta_{1}} A_{\mathrm{p}},
\end{aligned}
$$


leads to the reduced set of equations

$$
\begin{gathered}
\frac{\mathrm{d} N}{\mathrm{~d} t}=-N+\alpha-N A_{\mathrm{p}} \frac{T 1}{1+\mu_{2} T_{2}}-\phi N A_{\mathrm{p}} T_{2}, \\
\frac{\mathrm{d} T_{1}}{\mathrm{~d} t}=-T_{1}+v N A_{\mathrm{p}} \frac{T_{1}}{1+\mu_{2} T_{2}}, \\
\frac{\mathrm{d} T_{2}}{\mathrm{~d} t}=-T_{2}+v \phi N A_{\mathrm{p}} \frac{T_{2}}{1+\mu_{1} \frac{T_{1}}{1+\mu_{2} T_{2}}},
\end{gathered}
$$

$$
\frac{\mathrm{d} A_{\mathrm{p}}}{\mathrm{d} t}=\xi_{\mathrm{p}}(t)-A_{\mathrm{p}}\left(T_{1}+T_{2}\right),
$$
where the new parameters $\mu_{1}, \mu_{2}, \phi, \alpha$, and $\xi_{\mathrm{p}}(t)$ are related to the old ones by

$$
\begin{gathered}
\mu_{1}=\frac{c_{1} \alpha_{1} \gamma}{\delta \lambda}, \quad \mu_{2}=\frac{c_{2} \alpha_{2} \gamma}{\delta \lambda}, \quad \phi=\frac{\alpha_{2} \beta_{2}}{\alpha_{1} \beta_{1}}, \\
\alpha=\frac{\rho \lambda}{\gamma^{2}}, \quad \xi_{\mathrm{p}}(t)=\frac{\alpha_{1} \beta_{1} \varepsilon}{\gamma \delta \lambda} \omega(t) .
\end{gathered}
$$




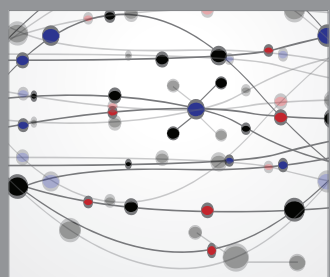

The Scientific World Journal
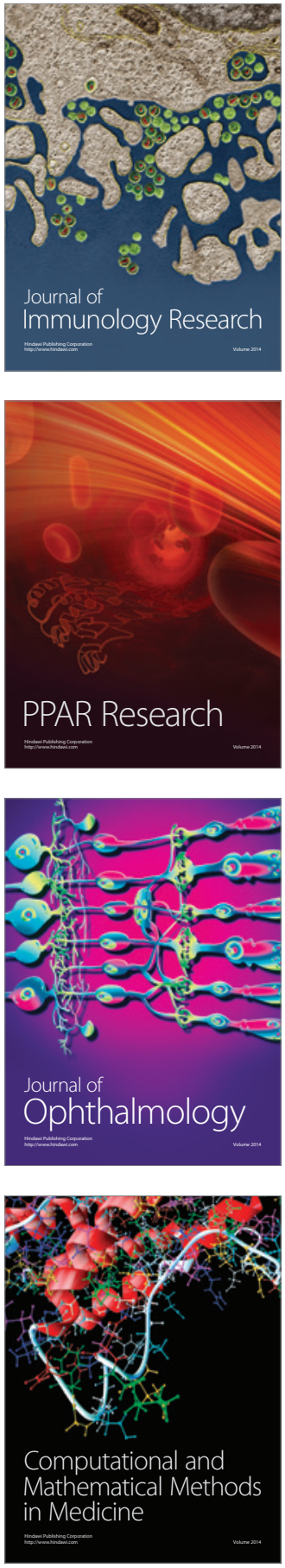

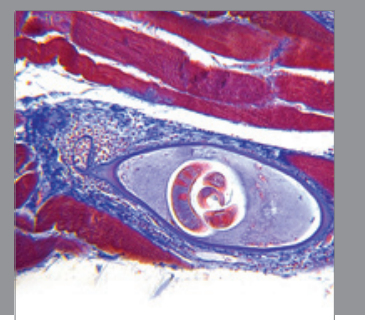

Gastroenterology

Research and Practice
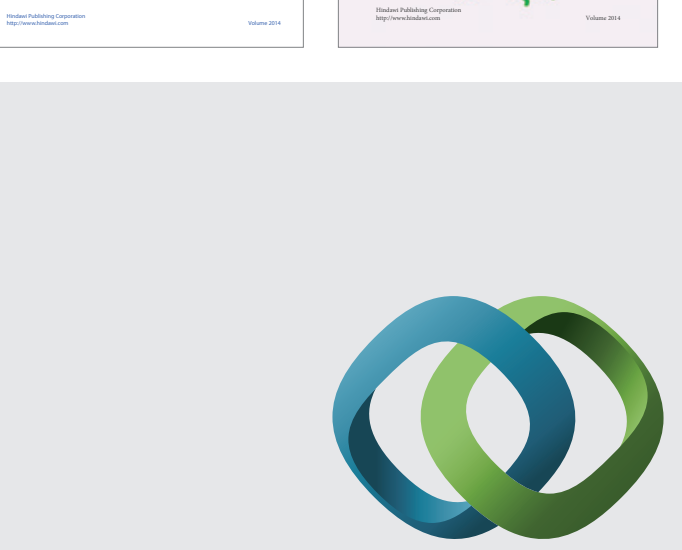

\section{Hindawi}

Submit your manuscripts at

http://www.hindawi.com
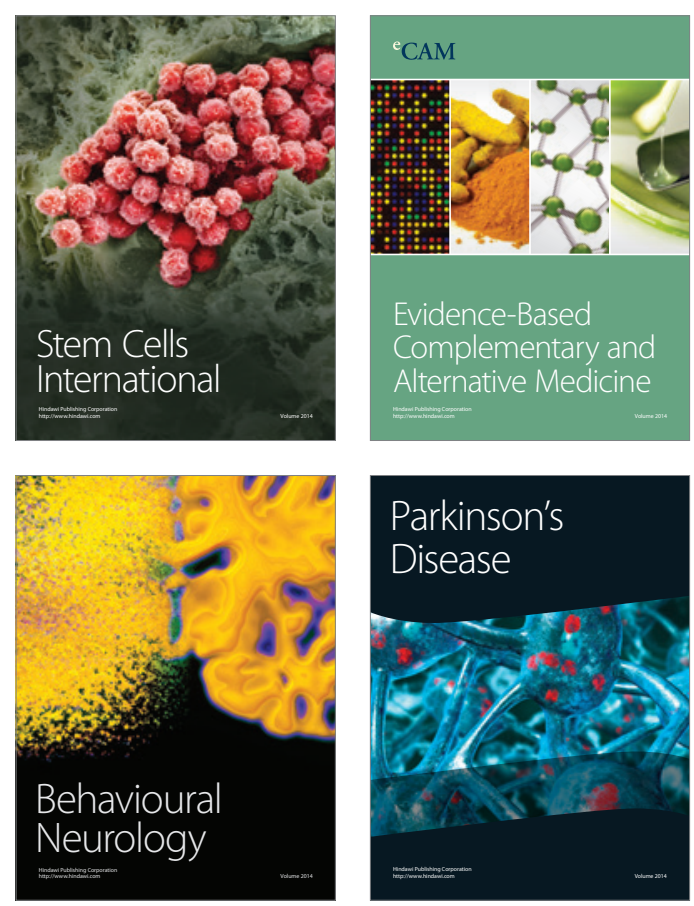

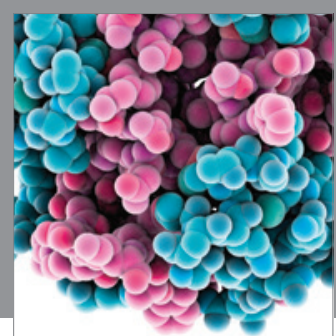

Journal of
Diabetes Research

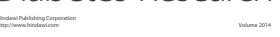

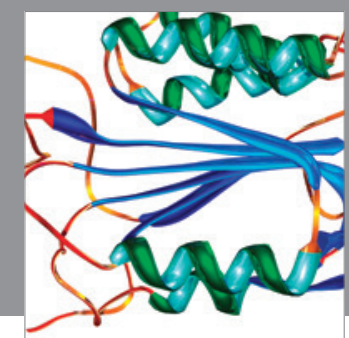

Disease Markers
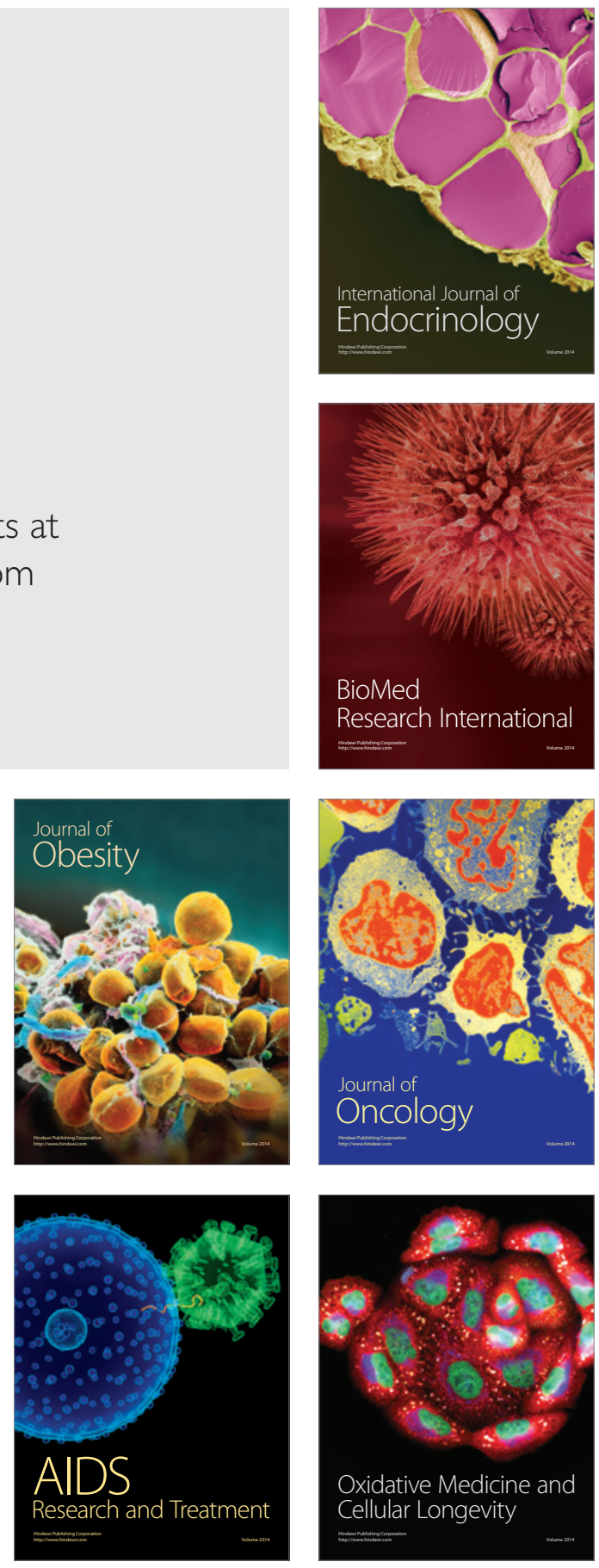